\title{
Modos de producción y modelos culturales. La experiencia del cruce en una fábrica hispano-japonesa
}

\author{
Rafael Cuesta Ávila \\ Universidad Autónoma de Yucatán \\ Mérida. México
}

Como etnógrafo, siempre me ha interesado lo que pasa en los cruces e intersecciones de la vida, dado que éstos constituyen un observatorio crucial para la reflexión antropológica. El cruce, y no me refiero solamente al espacial sino también al cultural, se caracteriza sobre todo por ser un ámbito ambiguo, ambivalente, indefinido, en el que los valores no están completamente cuajados, ni sedimentados, ni decantados, sino que se hallan aun entre-mezclados o con-fundidos, como el agua y el aceite. Este estado de intersección permite estudiar las antonimias y antagonismos, los contrastes y contradicciones generadas en un proceso de entrecruzamiento que trata de darle un orden a un caos.

En este sentido, las intersecciones transnacionales, en nuestro caso las empresariales, ofrecen un excelente "laboratorio" para observar la dinámica de los "choques inter-culturales" entre una firma matriz extranjera y un centro de producción filial autóctono, haciendo de la fábrica estudiada, Santana Motor, un lugar en donde entran en colisión distintas y distantes interpretaciones del mundo, la propia y la ajena. Los escenarios resultantes a esta interpenetración van desde la imposición de la matriz, a la negación de la filial, pasando por el sincretismo como solución intermedia.

El presente estudio es fruto de un trabajo de campo desarrollado en la ciudad andaluza de Linares (Jaén), concretamente en la factoría mencionada, en el que se trataba de analizar los procesos de cruce dentro del área de intersección (AI) entre:

- una cultura del trabajo autóctona (CTA) andaluza, donde los popularmente conocidos como "santaneros" poseían sus propias tradiciones laborales, modos de hacer, pensar y relacionarse, y

- una cultura empresarial foránea (CEF), en este caso encarnada por los gestores y técnicos de la transnacional Suzuki, de procedencia japonesa, que incorporaba a la fábrica andaluza sus propios métodos de gestión y técnicas de producción. 


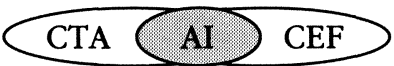

Ambos colectivos, trabajadores andaluces y directivos-técnicos japoneses, diferían culturalmente en los principios, presupuestos, premisas y presunciones básicas, bajo los que debía organizarse el trabajo fabril. Así, cada modelo etno-laboral suponía una manera diferencial de entender al individuo, a la sociedad y la relación entre ambos polos, y todo ello podía observarse dentro del espacio acotado de una fábrica de automoción. De este modo, podía contrastarse y constatarse cómo las relaciones de los japoneses con sus empresas se formulaban de manera diferente a las de los andaluces con las suyas. Ello permitía observar cómo:

- Si en Santana existía una cultura antropocéntrica o personalista, que concede un valor central al individuo (dado que "cada persona es un mundon), en Suzuki se constataba un énfasis en lo colectivo sobre lo individual, según el cual el todo debía ser superior y anteponerse a las partes. De cada una de estas formulaciones sobre la manera de entender el individuo se derivan distintas formas de interpretar valores culturales que afectan al trabajo, tales como la "creatividad", la "iniciativa", la "autoridad", etc.

- Si en Santana prevalece una sociabilidad basada en la segmentación, que los "santaneros" verbalizan como "clanes" o "camarillas", y en las redes personales; en Suzuki el ideal social se basa en la integración corporativa y en las redes formales-funcionales impersonales.

- Si en Santana se trata de alcanzar un punto de equilibrio entre trabajo y ocio, a través de la clásica fórmula del "trabajar para vivir y no vivir para trabajar", Suzuki concede una centralidad al trabajo como deber cívico o patriótico. La visión más hedonista y relativista del "santanero" entraba, pues, en contradicción con la más ascética y finalista del empleado japonés.

- Si en Santana hay una aceptación de la discrepancia respecto a las estructuras jerárquicas, admitiendo la negociación como vía para dirimir los conflictos entre dirección y trabajadores, a través de los sindicatos obreros, en Suzuki se destaca una interiorización acrítica de dichas estructuras jerárquicas, donde prima la vía de la imposición sobre la de la negociación a través del sindicato de empresa, como correa transmisora entre la dirección y los trabajadores.

- Si en Santana la participación del trabajador en el proceso productivo es interesada, es decir siempre a cambio de primas de incentivación, en Suzuki la participación del trabajador se entiende como voluntaria y gratuita. 
- Si en Santana existe una aceptación del error basado en la condición falible de lo humano, tal y como lo expresaba un trabajador: "No somos un robot, somos seres humanos y las personas nos equivocamos", en Suzuki se aprecia una aversión al error, basada en el ideal de superación o perfeccionismo continuo (kaizen, círculos de calidad), de tal modo que el individuo no falla, lo que realmente falla es el grupo de trabajo o el sistema, que están mal organizados.

- Si en Santana predomina el "presentismo" como manera de concebir el tiempo, pensando a corto plazo, viviendo al día, o improvisando sobre la marcha; en Suzuki se destaca la planificación o la programación del tiempo futuro.

Sobre todas estas concepciones culturales diferenciales, Ronald Doré (1989), un renombrado analista en las relaciones occidente-oriente, exponía la siguiente consideración: "Japón - decía- es el único país industrial avanzado cuya cultura tradicional no debe casi nada a los orígenes mediterráneos y a las tradiciones greco-latinas". En este sentido, la presencia de Suzuki en Santana implicaba progresivamente la sutil imposición de un modelo cultural diametralmente distinto al existente. Este cambio era entendido como necesario por la dirección japonesa, a fin de permitir el tránsito de la tradicional "Santana del rover" a la moderna "Santana del suzuki..

En este sentido, una de las cuestiones a abordar era si los "santaneros", como destacados exponentes laborales de la moderna industria andaluza, serían capaces de asimilar con éxito el reto que concitaban los nuevos métodos de trabajo y modelos de gestión propuestos e implantados paulatinamente por los técnicos y gestores de Suzuki. Para no quedarme en la cómoda indefinición de las medias tintas daré la respuesta como negativa. No obstante, esta negación precisa de una explicación que trataremos de ofrecer a continuación.

Cuando comencé el trabajo de campo, a principios de 1994, las relaciones entre Santana y Suzuki, tras casi doce años de convivencia, ya estaban francamente deterioradas. Recuerdo que cuando llegué a Linares -una vez que obtuve la financiación para el proyecto por parte de la Junta de Andalucía - desaparecía ante mi incrédula mirada el objeto de estudio que trataba de aprehender, tal como si fuera un espejismo que, al llegar a él, de repente se volatirizara. Y es que Suzuki acababa de declarar el cierre patronal de la fábrica de Santana y pasarían tres largos meses hasta que se volviera a reabrir, noventa días durante los cuales no pude acceder a la fábrica. En lugar de regresar por donde vine, decidí quedarme a observar lo que acontecía. Y lo que vi fue realmente interesante. Sobre todo participé en las movilizaciones populares para reivindi- 
car la continuidad de la factoría, lo cual me dio la posibilidad de conocer a bastantes obreros, empleados y dirigentes sindicales, que, una vez que obtuve la autorización de la dirección para poder estudiar los efectos de la intersección (lo cual no fue tarea fácil), me fueron de una valiosa ayuda. Al contrario de lo que pueda pensarse, los momentos de crisis son paréntesis excelentes para obtener datos relevantes y profundos que, en condiciones normales, no saldrían a la superficie o tardarían más tiempo en aflorar.

En este estado crítico, Suzuki se resistía a reabrir la fábrica hasta que los operarios aceptaran ciertos principios productivos irrenunciables. Los "santaneros", por su parte, respondieron con una huelga de protesta en la que se proclamaban manifestaciones como las que siguen:

"Suzuki quiere implantar en Linares técnicas de fabricación propias del Japón"; "Jaén no es Japón"; “En Linares somos andaluces, no japoneses"; "El modelo japonés no es trasladable ni a Santana ni a este país"; "Con este sistema acabaremos por trabajar en japonés con acento andaluz"; "El sistema de trabajo japonés es un fracaso y no resulta humano"; "No nos pueden meter con un calzador la filosofía oriental"; "Ya no es ésta [Santana] una empresa a la medida del hombre. Se ha deshumanizado"

Desde este punto de vista, los trabajadores locales acabarían interpretando la propuesta de Suzuki de "modernizar y racionalizar la producción" como "trabajar a la japonesa", asistiéndose en consecuencia a un corrimiento del plano técnico al plano étnico.

En este estudio trataremos de analizar tres aspectos cruciales derivados de este proceso de intersección entre los colectivos humanos de Santana y Suzuki. Por una parte, el papel a jugar por el individuo dentro del proceso productivo. Por otra, las implicaciones del cambio en el modelo tecnológico. Por último, abordaremos los efectos simbólicos aparejados a la introducción del nuevo producto fabricado.

\section{LA CONSIDERACIÓN DEL INDIVIDUO DENTRO DEL PROCESO PRODUCTIVO}

Antes de que llegaran los japoneses, en la fábrica de Santana prevalecía un modo de fabricación personalista, es decir, como hemos expuesto más arriba, se resaltaban aquellos valores de índole más individual y subjetivos, tales como la aniciativa personal", la "creatividad", la "originalidad", el "ingenio personal", la "improvisación", el "riesgo", la "manera personal de hacer las cosas", la "astucia", la "maña", la "autonomía personal,, la unventiva", la "habilidad"... Éste era el conjunto de valores que predominaban en la fábrica andaluza. 
La prevalencia de tales valores cualitativos de signo personal hizo que el "santanero" fuera convirtiéndose al paso de los años en un trabajador imprescindible o insustituible: llegado a un punto de experiencia laboral nadie conocía su puesto mejor que él. Cada uno poseía las "triquiñuelas", "ratonerías" y "atajos" propios de su oficio, y nadie como él sabía cómo sacarle partido a la maquinaria con la que llevaba trabajando quince años en su puesto fijo. En general, el "santanero" trabajaba en lo que en el argot se conoce como fuera de proceso, haciendo gala de aquel aforismo de "cada maestrillo con su librillo", como se me solía decir en los talleres. Además, todo este conocimiento laboral era de índole personal e intransferible, y pocas veces compartido. Todo ello proporcionaba al operario que tuviera dichas cualidades una razonable seguridad en su puesto de trabajo y una ventajosa posición de cara a plantear posibles reivindicaciones a sus superiores, que no podían cambiar a un trabajador por otro de la noche a la mañana sin causar un desajuste productivo. Nadie como él podía garantizar un resultado óptimo en un trabajo tan especializado como el que venía desarrollando desde hacía tanto tiempo.

Talleres productivos y oficinas técnicas mantenían en la "Santana del rover ${ }^{n}$ un prudente distanciamiento entre sí. Cada uno debía estar en su sitio y las fronteras sólo se traspasaban cuando era estrictamente necesario. Los técnicos de entonces, muchos provenientes del ICADE (Instituto Católico de Empresas), recluidos en sus distantes oficinas, desconocían la cotidianeidad del trabajo en los talleres. Además, dado que el producto que entonces se fabricaba, el todoterreno Land Rover, era de patente inglesa, cualquier innovación o modificación del vehículo era responsabilidad de los técnicos ingleses, que sólo aparecían por Santana para introducir un cambio y luego se marchaban de nuevo. Muchas veces el técnico español no sabía resolver problemas productivos en los talleres, por lo que se daba una primacía del conocimiento práctico del taller sobre el técnico de las oficinas, tal y como se expresaba en las siguientes frases, tan populares, entre los trabajadores: "Un mono vale por dos batas", en alusión al uniforme de cada colectivo; o un mono lleva dos batas enciman, dando a entender con ello que el obrero sabe el doble que el técnico; o "no hay mejor ingeniero que el propio operario", como reconocía un técnico de procesos de la empresa, aportando la siguiente argumentación:

En Santana hay hombres que conocen muy bien la máquina y saben quizás más que los técnicos que marcamos los tiempos y los métodos de trabajo. El ingenio de la gente siempre permite una mejora del método establecido. Y es raro el operario que no mejora el método que le pone el técnico, porque como aquí se dice: "no hay mejor ingeniero que el propio operario". Si tú te has tirado un mes 
mejorándole el método, ellos han buscado luego un utilillo casero que usan cuando tú te has dado la media vuelta, y hacen el trabajo en la mitad de tiempo que les distes. Si me tenían que dar cien piezas me las han dado pero con una hora de antelación.

Debido a ello, el "santanero", como productor individual, era el auténtico creador y depositario del conocimiento fabril. Su forma personal de enfrentarse a la producción no tenía por qué coincidir con el proceso marcado por los técnicos, que muchas veces ignoraban la solución apropiada al encontrarse ésta en la cabeza de los productores.

Cuando Suzuki se introduce en Santana incorpora un sistema de producción impersonal, donde se resaltan valores colectivos y objetivos, tales como "eficacia", "eficiencia", "productividad", "estandarización", "programación", "planificación", "normatividad", "despersonalización"..., dentro del cual las demostraciones de excesivo individualismo comenzaron a ser repudiadas y reprendidas. Según aquellos que tuvieron la experiencia de viajar a las plantas japonesas de Suzuki, los que no se ajustaban a esta premisa social eran objeto de burla y escarnio público. Ahora debía predominar el proceso técnico, la ortodoxia del método, la estandarización normada, la hoja de instrucciones, la integración corporativa, la disciplina interiorizada..., borrando cualquier rastro personal en el proceso productivo. El "Santanero" comenzaba a sentirse amenazado por la paulatina aplicación de aquel aforismo oriental que establece el temido principio igualitario de que "cualquier clavo que sobresale debe ser machacado".

Desde esta visión, en la que las partes son absorbidas por el todo, las singularidades habían de ser eliminadas, y la relación entre individuo y sociedad, o entre trabajador y empresa debían resolverse a favor del segundo término. En función de esto, el trabajador ideal de Suzuki debía ser intercambiable, reemplazable, polivalente y prescindible, una vez vaciado de prerrogativas personales. Cualquier trabajador con unos mínimos conocimientos prácticos, y un máximo sometimiento a los criterios técnicos exigidos podía integrarse plenamente en el nuevo sistema de producción. De este modo, los operarios más jóvenes ascendían más rápidamente en la escala profesional, ante el descontento de los más veteranos, que quedaban anclados en el antiguo sistema de valores laborales. De hecho, la estrategia de reclutamiento de Suzuki para fabricar sus propios modelos consistía en seleccionar a los sectores más jóvenes, mientras los "santaneros" más antiguos, y por consiguiente menos maleables, quedaban relegados a la fabricación del viejo Land Rover. De este modo, los más nuevos ascendían en el escalafón, mientras los más viejos se estancaban. El orden sociolaboral imperante hasta entonces se invertía, y ahora la veteranía ya no era un grado. 
El incumplimiento de los planes y plazos trazados por Suzuki hizo que el equipo técnico japonés asumiera el control absoluto del cambio tecnológico, desplazando para ello al cuadro técnico de Santana, con el consiguiente descontento de este personal que, escasos años atrás, comenzaba a asumir algunas iniciativas, una vez efectuada la compra de la patente inglesa del rover, que ahora pasaba a denominarse como Land Rover-Santana. Con la nueva dirección japonesa, cualquier actividad debía ceñirse estrictamente a los métodos diseñados desde el Departamento de Ingeniería de la Fabricación. De este modo, todo el proceso de fabricación pasaba a estar predeterminado desde las oficinas técnicas y los trabajadores no tenían más que seguirlo fielmente. A su vez, los técnicos españoles tenían que hacer cumplir las estrictas instrucciones de sus homólogos nipones. Con el nuevo sistema de producción, entraba un nuevo marco de valores que en buena medida se contraponía a los contemplados en los presupuestos tradicionales. Ahora la oficina técnica se imponía a los talleres, implicando todo esto un cambio en el sujeto productivo, entendido como un trabajador más homologable e impersonal.

\section{El CAMBIO DE PARADIGMa teCNOLÓGICO}

Desde su fundación, allá por 1954, Santana se había basado en un sistema de producción tecno-mecánico y manual, y esto había marcado el modo de trabajar de los "santaneros". Antes de la llegada de Suzuki, los trabajadores andaluces elaboraban un vehículo, que era el Land Rover, con un modelo de fabricación basado en una concepción del trabajo cuasiartesanal, una tecnología mecánico-manual y una fuerza laboral numerosa. Según la forma en la que se elaboraba el producto, el Rover era definido como "un mecano que se montaba pieza a pieza", muchas y pesadas, de forma acumulativa, lo cual exigía una mano de obra numerosa. Las características del Rover, con 2.000 tornillos que había que poner a mano, exigían en su fabricación una elaboración casi artesanal. En estas condiciones, cualquier intento por automatizar su producción hubiera sido impracticable por el alto coste exigido. Se trataba, pues, de un vehículo apropiado para una tecnología mecánica, basada en un masivo trabajo manual, circunstancia que por sí misma frenaba la aplicación de nueva tecnología. Este modo de fabricación mecánico-manual, plagado de deficiencias técnicas, hacía que cada uno de los vehículos manufacturados fueran casi singulares desde sus inicios a su acabado.

En opinión de los peritos de Santana - y esto es bastante significativo para comprender los procesos de fabricación del Rover- era la sol- 
dadura entre los tubos del chasis o bastidor el factor causante de unas mínimas deformaciones tubulares, y debido a esta pequeña anomalía, prácticamente ningún chasis salía idéntico a otro. De este modo, cuando se enfriaban los cordones de soldadura echados sobre los largueros y travesaños, tras ser expuestos a altas temperaturas, nunca lo hacían exactamente con la misma tensión, presentando inapreciables deformaciones que afectaban a la correcta alineación o nivelación del chasis, cuyas consecuencias afloraban posteriormente a lo largo del proceso productivo en determinados puestos de la cadena de montaje.

El bastidor, como base de montaje del vehículo, servía de plataforma sobre la que se iban agregando las distintas piezas, que eran ensambladas una tras otra, en un lineal proceso acumulativo. Cualquier variación o irregularidad, por mínima que fuera, en la elaboración del chasis, introducía modificaciones en el posterior encaje de las piezas a montar, que debían ajustarse a la peculiar desnivelación de las anteriores, y que de alguna manera iban particularizando el resultado, pudiendo decirse que cada vehículo acabado era un producto único y singular. Esta singularidad era una de las características que definían la labor del "santanero", y que le hacían identificar su trabajo mecánico-manual como artesanal, produciendo unidades diferenciadas en su especie. "No hay dos rover iguales", alardeaba el "santanero".

Por ejemplo, la forma del hueco de la puerta dependía de la alineación existente entre el lateral de la carrocería, el techo, el salpicadero y la aleta; alineación que variaba en cada vehículo. Con estas condiciones, el montaje de las puertas, que era realizado con ayuda de martillo y puntero, dependía del buen criterio del montador que, según estimase, retaladraba, improvisaba suplementos de masilla, ponía apoyos de tacos de goma para reequilibrar el desnivel, recortaba material, buscaba el acople de las piezas a fuerza de martillazos y golpes..., sin que estas operaciones estuvieran expresadas en la hoja de instrucciones del proceso, que si bien indicaban qué hacer (en este caso "ajustar puerta derecha") no especificaba cómo hacerlo. Era el "saber hacer" del trabajador, a partir de su criterio personal, el que resolvía esta cuestión, para lo cual gozaba de cierta autonomía irrenunciable en su trabajo. Los propios productores hacían abundantes referencias a esta cuestión:

Las puertas del rover se cuadraban a base de gato, hierro [palanca] y martillo. Si aun no quedaba equilibrada se le metían más arandelas en un sitio que en otro de la bisagra para levantarla más y que no quedase demasiado caída y le impidiera cerrar. Cada uno empleaba su truco para que la puerta acabara cerrando [...] Tanto era así que si le quitabas una puerta y le ponías otra, la nueva no encajaba. El hueco de la puerta estaba cortado y sellado de tal forma que no admitía nada más que la suya. 
De este modo se podía decir que cada puerta tenía su "firma" o forma de encajar según el trabajador que la cuadrara; es más, incluso existía la costumbre de estampar la muesca del número del operario sobre la pieza que fabricaba para individualizar su obra y dar a conocer a su autor, hábito que aun seguían practicando por su cuenta algunos trabajadores en distintos talleres.

En los faros delanteros, ocurría con frecuencia que uno solía quedar más alto que el otro, un descuadre que se apreciaba cuando se colocaba el paragolpes sobre ellos. El defecto se corregía torciendo o inclinando el paragolpes de un martillazo para hacerlo coincidir con los faros, procedimiento que no aparecía, desde luego, en las hojas técnicas. Las aletas de las ruedas también estaban desniveladas a razón de unos milímetros, diferencia causada por la herramienta que las elaboraba. Para cuadrar la aleta y comprobar que quedaba alineada se utilizaba una cuerda, y se medía a mano. Tampoco esto aparecía reflejado en las hojas de instrucciones. Las inexactitudes previas afectaban a su vez a las piezas que se montaban sobre ellas, por lo que los trabajadores de los siguientes puestos tenían que ingeniárselas para adaptar su trabajo a las peculiaridades arrastradas por el producto.

Con toda esta suma de "defectos", era evidente que el vehículo se montaba descuadrado, cada uno a su manera, aunque la acumulación de desajustes era corregida recurriendo a procedimientos no estandarizados, proviniendo en muchos casos de la capacidad de improvisación o del ingenio del trabajador, pero que permitían la "normalización" de los habituales desperfectos. Ante tantas variaciones, el trabajador acostumbrado en su puesto fijo a las distintas anomalías que pudieran presentársele, solucionaba el defecto que la propia oficina técnica a veces no sabía cómo resolver.

Gracias a estas artimañas incorporadas por los propios trabajadores en base, muchas veces, a su criterio personal, y por tanto no escritas en la hoja técnica del proceso, la falta de una perfecta alineación en el vehículo era corregida con ingenio, quedando reducida a una irregularidad tan pequeña que, aunque podía ser percibida por los productores, apenas era notada por los clientes. En resumen, y en estas condiciones de producción, el montaje dependía en buena medida de la habilidad del productor y de su experiencia personal, que, lógicamente, dejaba su impronta sobre el producto. De ahí la costumbre de marcar la propia pieza para diferenciarla de las fabricadas por los demás, plasmando su humanidad y personalidad en el trabajo realizado.

De este modo, la "profesionalidad" del "santanero" radicaba en su experiencia personal para reaccionar al mayor número de situaciones productivas posibles, corrigiendo con sus criterios personales las desviaciones 
arrastradas en razón de la deficiencia tecnológica entonces existente. Esto es bastante significativo, puesto que ponía de manifiesto la supremacía del conocimiento práctico sobre el de tipo técnico, dentro de un sistema tecnológico de carácter mecánico-manual, basado en la elaboración de productos que tendían a la singularidad. De ello resultaba un claro predominio del hombre sobre la máquina, de forma que el obrero era el sujeto activo mientras la máquina era el objeto pasivo, una relación binaria que se modificaría posteriormente con Suzuki. Este tipo de tecnología era compatible con los valores personalistas del "santanero", más centrados en la persona que en el sistema, dado que el obrero podía imponer su ritmo y dominio personal sobre el sistema de producción. La fábrica debía estar hecha a la medida del hombre.. Este antropocentrismo de profundas raíces greco-latinas, tan característico del "santanero", se manifestaba en frases tales como:

"Aquí somos hombres, no apéndices de una máquina, ni un robot. Hay que intentar dominar a la máquina para que la producción no te domine a ti"; «Como te domine la producción pasas a ser un resorte más del mecanismo y dejas de ser humano"; "Con el robot trabajas para la máquina y en el trabajo manual la máquina trabaja para tim.

La predilección por el trabajo manual frente al robotizado era unánimemente compartida por los "santaneros"; muy pocos discrepaban de este parecer. El bajo nivel tecnológico existente en Santana antes de la llegada de Suzuki, junto a la gran cantidad de mano de obra necesaria, hacía inevitable que cada trabajador fuera dejando su personal impronta sobre el producto, a medida que las piezas pasaban de mano en mano. De ahí la costumbre de marcar la propia pieza para identificarla o diferenciarla de las fabricadas por los demás, plasmando su "firma" en el trabajo realizado. Como expresaba un trabajador:

La forma de trabajar el rover era más artesanal y requería más de la habilidad del trabajador y de su experiencia, incluso de su picardía. No te valía cualquier trabajador para cualquier trabajo. Cada uno conocía a fondo su oficio porque eran trabajos más especializados que los de hoy.

Y otro:

El rover era un mundo completamente distinto al de suzuki. Se vivía de forma diferente a esto que tenemos ahora. Tenía su propio tiempo, su ritmo de trabajo, sus métodos, su orden de montaje [...] El mismo montaje era mucho más complejo. En los pisos, en las bases, en los asientos, en las puertas, te podía decir quién estaba montando qué cosa. Ahora es completamente impersonal, el más tonto monta lo que sea. 
Por ello, el "santanero" definía el Rover como "un producto que creaba trabajadores de oficio", un vehículo elaborado básicamente con las manos, casi artesanalmente y con limitados recursos tecnológicos, donde había que ingeniárselas día a día para sacar la producción. En estas condiciones, la habilidad manual y el aporte personal del productor eran determinantes para la realización del producto, permitiendo al obrero imponer su dominio y ritmo personal sobre el sistema productivo.

De este modo, la baja tecnología de entonces permitía un mayor protagonismo al trabajador en el proceso de producción a través de su "Saber hacer", de tal forma que al final no existían dos vehículos iguales. Buena parte del trabajo dependía del abuen criterio del operario, de manera que según sus apreciaciones personales se enfrentaba a la tarea productiva por su propia cuenta y riesgo. Ello hacía gozar al "Santanero" de cierto margen de autonomía, irrenunciable en su trabajo, y daba al obrero la consideración de "artistan. Esta aportación personal era imprescindible para la elaboración del producto tradicional.

En gran medida, el uso de una tecnología de tipo mecánico permitía la intervención directa del trabajador sobre la producción. El estrecho contacto entre producto y productor proporcionaba un profundo conocimiento empírico, basado en las propias experiencias sensoriales (tacto, vista, oído,...) consideradas fundamentales en un sistema de referencia, donde el obrero era el sujeto activo y la máquina el objeto pasivo. Su pericia y saber hacer facultaban al "Santanero" a introducir ciertas variaciones personales sobre un modelo técnico a todas luces insuficiente, resolviendo sobre la marcha aquellas contingencias e imprevistos que se fueran presentando durante el proceso de fabricación.

En la "Santana del rover" las primeras hojas de instrucciones eran muy rudimentarias y describían con poca precisión la lógica operativa del proceso, por lo que el productor gozaba de un amplio margen de autonomía en su actividad. Posteriormente, ya en la última etapa del Rover, coincidiendo con la incorporación de Suzuki, se cayó en el extremo contrario, en el exceso de contarlo todo detalladamente, operación por operación, "como si fuera una novela" ("echar apriete rápido, situar la pieza encima del útil...n), proporcionando una vasta información técnica, por lo común accesoria, que cada trabajador terminaba adaptando a su propia manera de proceder. Estas hojas no estaban directamente a la vista de los trabajadores sino que se encontraban en poder de los encargados o de los supervisores que eran quienes controlaban el trabajo realizado por los operarios.

Con la llegada de Suzuki se introduce un nuevo paradigma productivo basado en un sistema de producción tecno-automático y robótico. La producción de los nuevos vehículos incorporados por la firma japonesa 
(los modelos Samurai y Vitara), exigían mayores cotas de automatización y robotización, junto a una importante re-informatización en el ámbito de toda la fábrica, alterándose con ello las bases tradicionales de los modos de fabricación de la factoría andaluza.

En este nuevo sistema de referencia tecnológica, el productor se convertía en el sujeto pasivo y la máquina en el objeto activo, que ejerce la acción transformadora, mientras el obrero se limitaba a tareas de supervisión, eliminándose con ello el "eslabón humano" que mediaba entre los medios de producción y el producto. A juicio de los trabajadores, cuando el sistema de producción domina el trabajo humano el trabajador acaba perdiendo su preciosa autonomía personal para quedar reducido a un ser pasivo, dependiente del dictado computerizado de la máquina. En este momento, los "santaneros" empezaron a sentirse anulados dentro de un sistema impersonal, en manos de un pequeño grupo de dirigentes que apostaba por la razón productiva, ignorando las consideraciones sociales.

La máquina automática tiende a reducir la complejidad del trabajo, arrebatando al "santanero" un valioso saber de oficio, tan característico del sistema de fabricación mecánico, que le proporcionaba una razonable seguridad en el puesto. De hecho, la tecnología automática produce operarios intercambiables y no imprescindibles, que no necesitan de una larga preparación. Por ello, el avance en el proceso de automatización que simplificaba el trabajo del obrero, acabó traduciéndose en una descualificación laboral que restaba fuerza y presión al "Santanero" para poder reivindicar sus demandas individuales o colectivas frente a la dirección, viendo con ello amenazado su puesto de trabajo, en una situación donde las máquinas se imponen sobre las personas y en la que los trabajadores cualificados van dejando de ser necesarios para la buena marcha de la empresa.

Con Suzuki, la fabricación se vuelve altamente estandarizada, basada en la aplicación estricta del método y de las normativas establecidas desde las oficinas técnicas, como única vía de fabricación válida a la que debe ajustarse todo operario de taller, evitando cualquier desviación o improvisación sobre le único método posible: el técnico. El "santanero" debía basar literalmente su actividad en las consignas proporcionadas en las hojas de instrucciones técnicas, situadas en carteles colocados en sus puestos de trabajo o en tablones cercanos. Ahora, la aportación humana se limitaba al máximo, quedando excluida cualquier iniciativa personal que no se ajustara a las estrictas instrucciones técnicas de los procesos. A partir de este momento, los trabajadores debían amoldarse a los modos de fabricación exigidos por Suzuki, cuyo equipo técnico tomaba las riendas de la producción, mientras el equipo gestor ocupaba la dirección, desplazando a la autóctona que se sintió cesada y arrinconada. A partir de este mo- 
mento ya no cabía la vía de la negociación que de alguna manera había permitido la dirección española.

Con el nuevo sistema de producción de Suzuki se tendían a difuminar las diferencias personales, de tal modo que los profesionales artesanales del Rover ya no tenían cabida en el sistema de producción, y, así, criticaban con desencanto: "con el suzuki [haciendo referencia al vehículo] se ha perdido el oficio y la profesionalidad. Existe así la convicción de que el grado de profesionalidad ha descendido en relación inversa al avance tecnológico incorporado por Suzuki. La tecno-automatización impone una igualdad y una equivalencia de saberes que los "Santaneros" interpretan como un paso hacia la descualificación. En opinión de un trabajador:

Con las máquinas nuevas el trabajador no tiene que llegar a poseer el grado de conocimiento que se tenía antes. La máquina lo hace casi todo. Si introduces una pieza mal situada, antes la máquina no te avisaba. Ahora no necesitas estar encima, la máquina te indica el error. Antes la calidad de acabado se hacía en base al "manitas". Ahora la máquina te da la calidad pero a costa de esa profesionalidad que poco a poco se va perdiendo.

\section{Otro compañero apostillaba:}

Las máquinas hacen el trabajo y los trabajadores supervisamos cómo trabajan las máquinas. Cuando acaba, sacas la pieza, metes otra, y aprietas un botón: ¿Qué queda del oficio?

\section{LA INTRODUCCIÓN DE UN NUEVO PRODUCTO}

La identificación entre producto y productor, tan estrecha entre el Rover y el "santanero", tras más de 30 años de trabajo sobre el vehículo, se basaba justamente en aquella incorporación de un aporte personal como valor añadido, a través del cual el trabajador ofrecía su propia aportación individual dentro de una obra colectiva de la que él mismo formaba parte reconocible, en un vehículo que se decía: "hecho por nuestras propias manos".

Como consecuencia de este alto grado de identificación, el "santanero" ejercía una especie de sentimiento de pertenencia sobre el todoterreno Rover, de modo que a diferencia del posterior producto japonés, tal y como lo expresaba un productor: "el plano del rover lo tenemos en nuestras cabezas, mientras que el plano del suzuki está en el papel.. La fabricación del Rover había llegado a interiorizarse de tal modo por el "santanero", que éste había desarrollado una especie de apropiación mental hacia un vehículo que era considerado como algo propio, dado que su aportación personal era imprescindible para la elaboración del producto. 
Inaugurada la década de los 80 , y tras varios años de remodelaciones productivas, la firma japonesa comenzó a montar en las nuevas instalaciones fabriles de Santana su primer modelo, el "Samurai. Las primeras unidades salieron al mercado en marzo de 1985, fabricándose en paralelo con el Rover, cuya producción iría reduciéndose hasta llegar a desaparecer en 1995, derrumbándose con ello todo un mundo laboral soportado sobre ciertos pilares culturales. Pese a los iniciales temores de ciertos trabajadores, la fabricación de este primer modelo no introdujo un cambio drástico en las formas de producción sino más bien modificaciones graduales. El sistema de elaboración no difería en gran medida del llevado a cabo con el Rover, basado en una tecnología eminentemente mecánica y en la aportación manual del trabajador.

El salto cualitativo se produjo ya con la fabricación del nuevo modelo "Vitara", en 1987. La producción del nuevo vehículo exigía mayores cotas de automatización y robotización, junto a una importante re-informatización de toda la fábrica, alterándose con ello las bases tradicionales de los modos de fabricación de la factoría andaluza. Con el nuevo soporte tecnológico, el producto Vitara demandaba ahora de unas condiciones de fabricación altamente estandarizadas, debiendo ser excluida cualquier iniciativa personal que no se ajustara a las estrictas instrucciones técnicas de los procesos. Lejos de adaptar la producción a la forma de trabajo imperante en Santana, como se había consentido en el Samurai hasta ciertos límites, ahora los trabajadores debían amoldarse a los modos de fabricación exigidos por Suzuki, para lo cual el equipo técnico japonés asumía el control absoluto del cambio tecnológico, desplazando para ello al cuadro técnico de Santana.

Con el nuevo vehículo de procedencia japonesa se rompía la vinculación sentimental que unía al productor con el producto, que ahora pasaba a ser identificado como un vehículo ajeno que no encajaba con el tradicional "saber hacer" del "santanero". En este sentido, la elaboración del Suzuki-Vitara pasaba a ser concebida como un proceso extrínseco en donde el productor, lejos de aportar algo de sí mismo, debía limitarse a copiar o a reproducir milimétricamente las normas e instrucciones recibidas desde las oficinas técnicas, sobre un producto ahora sentido como extraño.

La primacía del conocimiento técnico de los ingenieros japoneses sobre el saber práctico de los operarios andaluces debía traducirse en un producto seriado y homogéneo, anónimo e impersonal, siendo cada uno "fotocopia" idéntica del original, donde no se aceptaba ninguna diferencia de un vehículo a otro, pues todos debían ser exactamente iguales al modelo prototípico. Ahora, cada unidad diferenciada del prototipo debía regresar al taller de revisión para ser reajustada. De este modo, cualquier discordancia de la unidad fabricada respecto al modelo diseñado debía entenderse como un error o anomalía, y no ya como una singularidad. 
El nuevo vehículo indiferenciado perdía a los ojos del "santanero" el valor artesanal de la obra humana, suplida ahora por la producción seriada y estandarizada, elaborada por el brazo articulado del robot. Los nuevos niveles tecnológicos introducidos, mediante la soldadura por robot, evitaban cualquier defecto de deformación inicial del chasis. La carrocería ya no era un "mecano" de piezas, sino una "monocabina" formada por unos pocos y grandes conjuntos que se abrochan perfectamente al chasis, sobre el que se incorporan los conjuntos mecánicos del motor, según un procedimiento estándar dictado explícitamente por la oficina técnica, desestimando cualquier criterio personal y subjetivo que no se ajuste al propuesto por los métodos diseñados por el Departamento de Fabricación.

Así, en la hoja técnica del vehículo suzuki se expone con todo lujo de detalles la forma de desarrollar las sucesivas operaciones, en unas instrucciones que el trabajador debe seguir literalmente. Más que la literatura, como ocurría con el Rover, se destaca en estas hojas el dibujo técnico, que ilustra y describe gráficamente lo que hay que hacer con una economía de palabras. Las pocas que hay, en muchos casos escritas en japonés, hacen referencia escueta al tipo de útil o herramienta que ha de usarse, algunas observaciones sobre las condiciones de trabajo, y poco más; resaltándose los puntos críticos de las operaciones que deben observarse especialmente para evitar defectos. Todo lo necesario debe ser explicado con la mayor simplicidad formal, para que el trabajador se ciña estrictamente al método sin necesidad de "tantear" otras alternativas posibles en función de interpretaciones subjetivas. Estas hojas de instrucciones se hallan colocadas sobre tablones o en el mismo puesto de trabajo para que puedan ser examinadas directamente por el productor, sin necesidad de recurrir a otras instancias. Además, esta referencia visual permite un rápido aprendizaje de la ejecución del trabajo.

En este sentido, Suzuki reclamaba del "santanero" la aplicación estricta del método estandarizado bajo las normativas establecidas, como única vía de fabricación válida, a la que se debe ajustar todo operario, evitando cualquier improvisación o desviación sobre el único método posible. Todo debe hacerse según lo dispuesto en la hoja técnica de instrucciones. Los procedimientos están claramente detallados, descritos, dibujados y expuestos en las inmediaciones del lugar de trabajo. Los operarios sólo tienen que seguir fielmente unas instrucciones que deben acatar sin salirse un ápice del "guión técnico. Todo ello induce a una preferencia por un pensamiento de tipo estandarizado, despersonalizado y reproducible según unos criterios normados. Todo el proceso de fabricación estaba predeterminado desde las oficinas técnicas y los trabajadores no tenían más que seguirlo. De esta manera, la programación calculada debía prevalecer sobre la improvisación espontánea. 
Con el tiempo, a medida que disminuía la aportación personal del productor, y sobre todo tras desaparecer el Rover definitivamente, se pasa a fabricar un producto sentido como "anónimo" e "impersonal. A juicio de los "santaneros", el nuevo sistema de producción introducido por Suzuki "despersonalizaba" y "deshumanizaba" la actividad laboral, al imponer la primacía de la razón técnica desde instancias externas al propio trabajador. A su parecer, los japoneses interpretaban su falta de ortodoxia productiva como una falta de disciplina y de lealtad hacia la empresa, que afectaba a la calidad final o de acabado de su producto.

Aparece entonces entre los "santaneros" un discurso en que se resaltaba el contraste étnico entre ellos y nosotros, a través de la emergencia de una conciencia de alteridad. De este modo, el encuentro entre dos culturas fabriles diferentes en un mismo centro de producción incitaba a la comparación con "lo ajeno", permitiendo una reflexión etnocéntrica que conducía al reconocimiento y revalorización de "lo propion:

"Ellos nunca improvisan. Todo tiene que salir como está programado. Nosotros decimos: vamos a plantearlo así y ya veremos cómo sale. Cuando los japoneses nos escuchaban decir eso de "ya lo veremos sobre la marcha", parecían desconcertados"; "Recibíamos fuertes broncas de los japoneses por no hacer las cosas sobre el plano, tal y como ellos querían"; "Parece que con este estilo de trabajo ahora fuésemos más japoneses que andaluces".

Un técnico de ingeniería lo expresaba así:

El japonés coge la línea recta y no se sale de ella, no improvisa nunca. Sigue a rajatabla el proceso sin desviarse, y no sólo eso, sino que si lo consigue mejorar lo comunica inmediatamente para que tomen nota de que aquel tiempo ha conseguido rebajarlo. Ya no vale tres minutos montar aquella pieza sino dos y medio, porque él ha dicho que haciendo qué cosa, se puede reducir el tiempo de la operación y todo el mundo se tiene que acoplar al nuevo método. Aquí no. El "Santanero" si consigue mejorar el método que le ha puesto el procesista o el técnico de tiempos se lo calla, retiene para sí ese conocimiento, prefiere esa ganancia, coger la prima y si le sobra una hora, pues para su salud o para su descanso. Esa es la mentalidad. Eso le chocaba mucho a los japoneses cuando vinieron al principio.

El "Santanero" se autodescribe como un trabajador creativo, ingenioso, espontáneo, improvisador, mañoso, autónomo, y estas cualidades se entienden preferibles a las representadas por los trabajadores japoneses, identificados con valores tales como la constancia, la programación, la normatividad, la integración, la disciplina, la fidelidad a la empresa. Para el trabajador andaluz, Suzuki no debía imponer su modelo de productor, pues evidentemente ellos no eran japoneses, ni querían serlo. Ante este descontento generalizado, los representantes sindicales, apoyados por la 
casi totalidad de los operarios andaluces, emprenden una actitud de resistencia pasiva por mantener vivo el modelo industrial heredero del Rover. Así, pese a los cambios introducidos por Suzuki, la forma de hacer el producto se mantuvo constante, como exponía este trabajador: "Con los japoneses seguíamos montando el vitara al estilo del rover [...] Se acataba la norma de modo superficial, pero en el fondo no se cumplía. Esta actitud suponía un motivo constante de enojo e irritación para los directivos y técnicos japoneses que acabó haciendo frustrar el proceso de intersección iniciado con entusiasmo por ambas partes. La incomprensión cultural fue el detonante de esta experiencia fabril fallida en el cruce.

Aunque los japoneses acabaron abandonando físicamente la fábrica andaluza, reemplazados por una nueva dirección "catalana" auspiciada por la Junta de Andalucía, que se convertía ahora en la nueva propietaria de la factoría para evitar el cierre y los perniciosos efectos socio-económicos que implicarían para Linares y su área de influencia, la presencia de Suzuki continuaría haciéndose efectiva a través del producto que dejaban, los métodos de trabajo, la tecnología, los tiempos de los procesos. De este forma, para el "santanero", los japoneses siguen controlando la fábrica a distancia, 'a control remoto', desde miles de kilómetros. Ante esta situación, al "Santanero" no le quedaba más remedio que claudicar ante la imposición de Suzuki, a fin de permitir la pervivencia de la fábrica y de la ciudad de Linares, renunciando para ello a buena parte de la propia cultura del trabajo y a su identidad laboral. Como expresaba un productor:

Nosotros arrastrábamos costumbres de atrás que van a ser difíciles de erradicar. Pero trabajando así no se puede competir. Entonces hay que trabajar de otra forma, como se trabaja por desgracia en el resto del mundo. Y eso supone renunciar a unos hábitos contraídos que deberán ser corregidos paulatinamente.

Para otros, aún quedan algunas leves esperanzas de seguir aspirando a conservar parte de la "cultura industrial" del "santanero" sin cerrarse a las innovaciones tecnológicas y organizativas, tan necesarias para la continuidad de la fábrica. Actualmente, todas las ilusiones de los trabajadores se hallan depositadas en el resurgimiento de un nuevo modelo del extinguido vehículo Rover, cuyo prototipo con modificaciones y mejoras, parece que ya ha sido experimentado con éxito. A este proyecto es al que se aferran los "santaneros", para quienes en lugar de "copiar las cosas de fuera y dejar perder lo nuestro", debería apostarse por "el mantenimiento de un vehículo propio que no está sujeto a los caprichos multinacionales. El entusiasmo y la predisposición existe en los trabajadores, y sin duda, recuperar el Rover sería un revulsivo para la empresa, aunque sin volver a las formas de fabricación tradicional, practicadas en el viejo vehí- 
culo que, desgraciadamente, ya no garantizan la supervivencia de la factoría en un sector tan competitivo como el de la automoción.

A manera de conclusión, cabría plantearse que los modos de producción expuestos no son sino una proyección o representación sociocultural de cada grupo humano, que acaba siendo trasladada al recinto fabril. Por una parte en Santana, cada producto, cada productor, e incluso cada maquinaria (cuyos "trucos" sólo eran conocidos personalmente por el operador), tendían a resaltar su singularidad en forma de sujetos y objetos diferenciados, a través de una tecnología mecánica que permitía un mayor margen de intervención humana en el proceso productivo. Por otra parte, en Suzuki, tanto el producto, como el productor, como el proceso de producción, tienden hacia la estandarización, en forma de sujetos y objetos indiferenciados, a través de una tecnología automática que limita la intervención humana en el proceso productivo.

De esta forma la fusión empresarial prevista en el cruce o área de intersección acabó por enmarañarse en una gran con-fusión cultural que imposibilitaba la mutua compresión entre andaluces y japoneses. Ambos polos valorativos, tan extremos entre sí, parecían difícilmente reconciliables si no se tendía un puente de entendimiento intercultural que, al menos, permitiera la solución del sincretismo. Por ello, y partiendo de esta experiencia real, sería recomendable que todo proceso de interpenetración, ya sea económica o de otra índole, estuviese respaldado por un previo análisis cultural, dado que la cultura cuaja todo un cimiento constituido por valores intangibles que suelen ser obviados desde las visiones más economicistas, pero sin los cuales difícilmente se sostiene toda la construcción tangible posterior. Desde este punto de vista sería deseable que toda firma empresarial contara junto con los ingenieros, economistas, psicólogos, sociólogos, con el apoyo de los antropólogos dedicados a la cuestión cultural. Así se evitarían muchos roces y tiranteces a los que no se encuentra una aparente explicación aplicando ópticas desenfocadas y miopes.

\section{BIBLIOGRAFÍA CITADA}

BENEDICT, RUTH. 1974. El crisantemo y la espada. Madrid: Alianza.

CUESTA Ávila, RAFAEL. 1997. Japón en Jaén: intersección de identidades en un centro de producción fabril. Tesis doctoral inédita.

DORÉ, RONALD. 1989. Fábrica británica, fábrica japonesa. (Los orígenes de la diversidad nacional de las relaciones laborales). Madrid: Ministerio de Trabajo y Seguridad Social.

Sugrta, Kurumi et JacQues Magaud. 1991. "France-Japón. Un produit, deux facons de fairem. Conventión d'étude CEE/ADR du 31 Julliet 1990. Centre d'Etudes de L'émploi. Dossier de Recherche 43. 


\begin{tabular}{|c|c|c|c|c|c|c|c|c|c|c|}
\hline 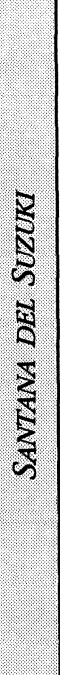 & 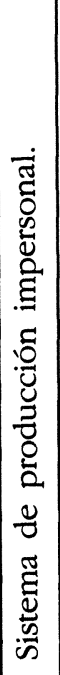 & 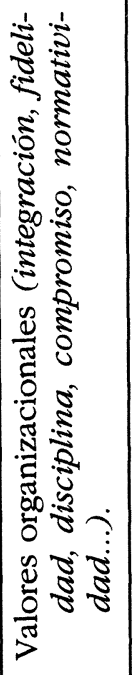 & 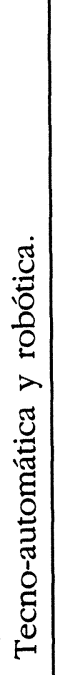 & 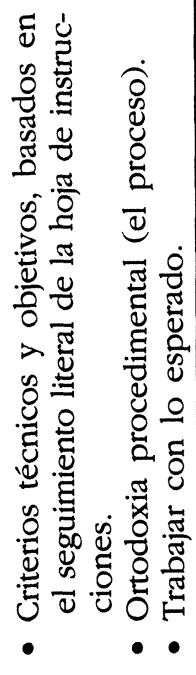 & 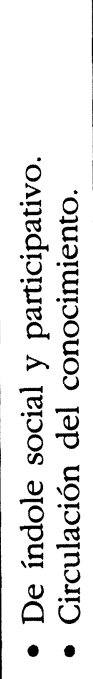 & 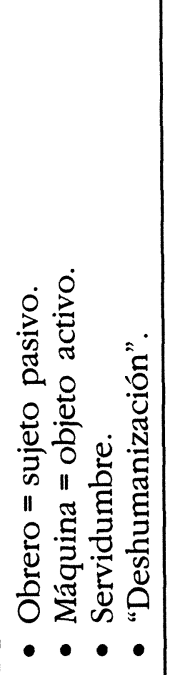 & 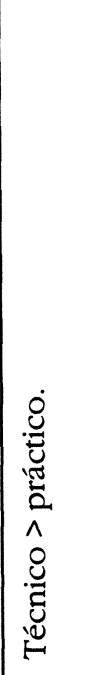 & 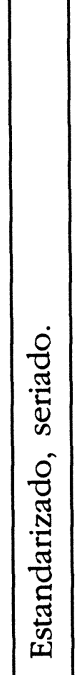 & 恋 & 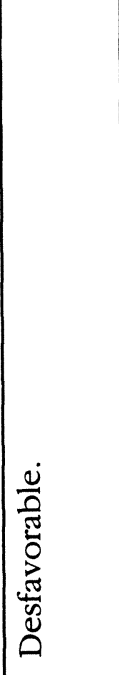 \\
\hline 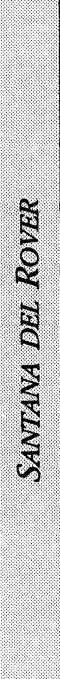 & 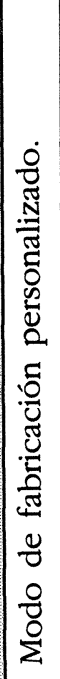 & 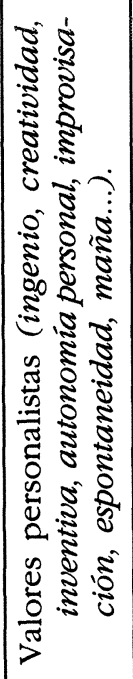 & 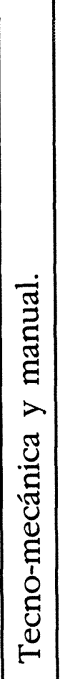 & 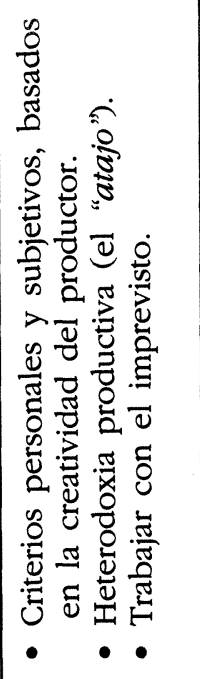 & 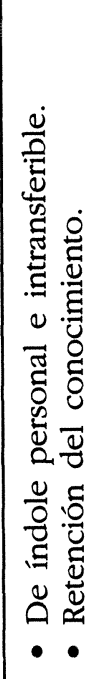 & 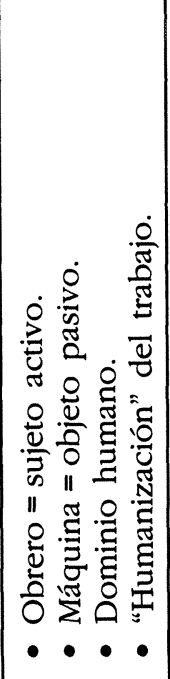 & 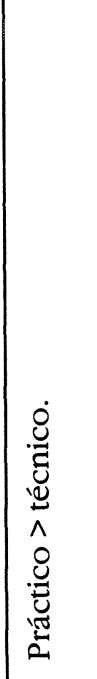 & 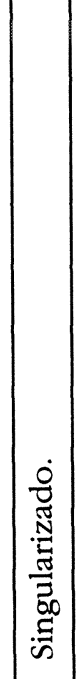 & 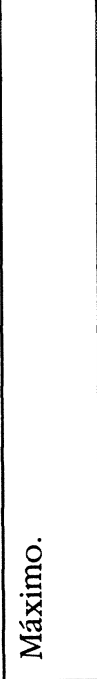 & 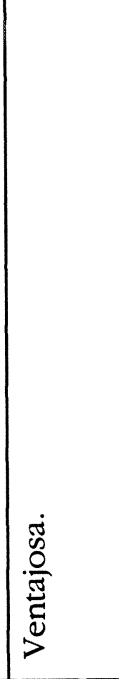 \\
\hline & 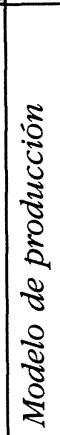 & 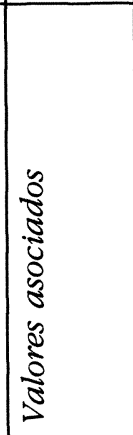 & $\mid$\begin{tabular}{|c}
$\mid$ \\
0 \\
0 \\
0 \\
0 \\
0 \\
0 \\
0 \\
0 \\
0
\end{tabular} & 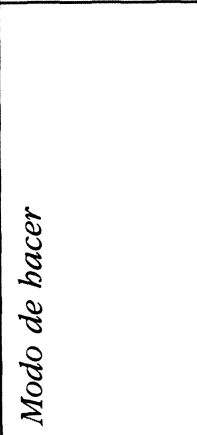 & 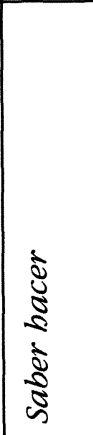 & | & 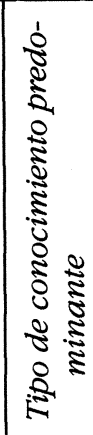 & 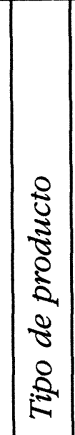 & 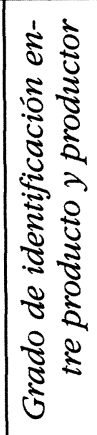 & 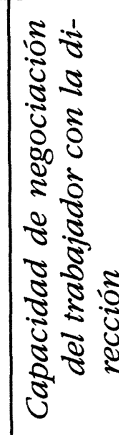 \\
\hline
\end{tabular}

